\title{
Towards Complexity Competence in Public Research Administration - A Case from the Environmental Sector in Finland
}

\author{
Jouko Inkeröinen ${ }^{1}$ \\ ${ }^{1}$ Kvantum Institute, University of Oulu, Finland \\ Correspondence: Jouko Inkeröinen, MSc, Research coordinator, Kvantum Institute, University of Oulu, P.O. Box \\ 7300, 90014, Finland. Tel: 358-4-0577-6106. E-mail: jouko.inkeroinen@oulu.fi
}

Received: January 8, 2022 Accepted: February 16, 2022 Online Published: March 4, 2022

doi:10.5539/par.v11n1p11 URL: http://dx.doi.org/10.5539/par.v11n1p11

\begin{abstract}
The basic elements of evidence-informed policymaking are the evaluation of existing research information, the acquisition of new research information, hearings of experts, and assessing alternative policy measures. In Finland the steering of public research is based on the procurement process where ministries are purchasers. This paper reports an interview with key persons from the structural development period of Finnish sectoral research (19902013). The competence needed from key actors in the steering of contract-based research is a multidimensional concept including sectoral, horizontal, and vertical components. This commissioning competence has evolved during the development period close to a complexity competence. The research management needs multidimensional knowledge, and the steering of the research requires skills in network governance and uncertainty management. Thus, it is not only research and sectoral competence that is needed from the administration, but also cross-sectoral, vertical and network management competence. The framework of the coordination and governance of complex research administration is introduced by applying the resilience concept.
\end{abstract}

Keywords: commissioning competence, evidence-informed policymaking, public research, research management, resilience

\section{Introduction}

Public spending for research and development is a tool for government policy in areas of science, technology, and innovation. On average, public funding constitutes $35 \%$ of total R\&D spending in European countries (Reale 2017). Funding is an instrument accessible to governments for steering science and innovation systems. Many countries have introduced reforms of their R\&D funding systems, to foster excellence, knowledge transfer and socioeconomic innovation. The changes typically reduce the proportion of institutional funding and favour competitive project-based systems (Reale 2017). This process can be seen in Finland, where the sectoral public research, conducted in collaboration with ministries and carried out by research institutes, has formed the central part of societal expertise, development, and the service system. In this article, we use the term commissioning to refer to both the management of public institutional and program funds and the procurement of research and research services therein. In Finland, this is done by the ministries and partly by large research funding agencies. It is like the purchase-provide model of purchasing but is more of a general and wider concept.

Key players in sectoral public research in Finland are state-owned research institutes. The total amount of R\&D funding for research institutes from their own administrative branches' budgets for 2019 was EUR 183.5 million. Budget funding decreased by around three per cent or EUR 5.6 million from the previous year's budget. Total R\&D funding for research institutes (budget funding and external funding) is EUR 457.2 million in 2019, which is EUR 3.3 million more than in 2018. The increase is due to increased external funding, which grows by EUR 8.9 million to EUR 273.7 million. The share of external funding is around 60 per cent of research institutes' funding (Official Statistics of Finland 2019). The policy measures of all the societal branches of the administration, practical administration work and international cooperation use the expert support and services of these research institutes. Budget funding and now more frequently R\&D programmes are tools for steering public research (Rantanen 2008). Therefore, research executives and responsible officials are key actors in the management of the commissioning of societally relevant knowledge for science-based or evidence-based policymaking.

Evidence-based policy (EBP) is a concept applied in public policy to refer to situations whereby policy decisions are informed by established objective evidence. Underlying many of the calls for evidence-based policy is often a 
(stated or unstated) scientific good practice, reflecting the belief that social goals are best served when scientific evidence is used comprehensively to inform decisions. The move towards EBP has its roots in the larger movement towards evidence-based practices (Banks 2009). The basic elements of EBP are the evaluation of existing research information, the acquisition of new research information, listening to experts, and presenting and assessing alternative policy measures (Academy of Finland 2009:256, Brownson et al. 2009a, 2009b). However, EBP as such is applicable for quite narrow fields such as medicine and it has faced criticism for its overly linear and therefore unrealistic approach (Cairney 2016, Head 2010). EBP is being replaced by softer definitions like or science-based decision-making (von Winterfeldt 2013) or evidence-informed policymaking (Topp et al. 2018).

\subsection{The Case Description-A Need for Commissioning Competence in Finnish Public Research Structure}

In the past 30 years, the Finnish public research system has been undergoing structural reform making it less fragmented and more cross-sectoral, aiming for a more societally relevant form (Lemola 2002, Hyytinen et al. 2009, Loikkanen et al. 2010). This objective of more horizontal coordination has also been the trend in public administration in general (Virtanen 2016, OECD 2017). The development of public sectoral research has been based on the systemic concept of national innovation policy and the general model of public sectoral research. In the General model, commissioning plays a major role. Public funding is channelled through public tendering by competitive funding mechanisms. The ministries serve as the commissioners of the sectoral research, and they can purchase research from different actors also from other sectors. Public sectoral research can also be conducted at places other than state research institutes, for example at universities. The original objective of the General model was to create a research market that would also reform the operating structure (Science and Technology Policy Council 1993, 1996). In the 1990s, performance control was introduced into public administration, which in practice meant that public research institutes were subordinated to ministries and the sectoral structure appeared to be strengthened. This was counter to growing horizontal information needs. Since then, Government decisions (2005, 2007 and 2013) have restructured the sector-specific research arena.

At different stages of this development, the lack of commissioning competence (CC) has been considered a weakness of public research implementation. Several rapporteurs have emphasised that an improvement in CC would be the key to getting better formulation of research needs (the needs of the government and ministries). When Commissioning competence is at high level, the ministries and other utilisers of the research are able to get and use the research information fully in the management of their own tasks - commissioning competence is working." (Prime Minister's Office 2006, translated by this article author). In response to the recommendations, ministries have improved their expertise by appointing research managers or research officials and participating in the design and management of societally relevant research programmes and public-private initiatives.

To improve the cross-sectoral cooperation between research purchasers and providers, the Advisory Board for Sectoral Research (2007-2011) was founded within the Ministry of Education. In this development 'model', there were consortia on both the purchaser and provider sides. The purchasers were the ministries and public funding organisations jointly, and the providers were supposed to be research institutes, universities, and private actors. This Advisory Board model was a strongly network-based solution. One of the board's objectives was to improve CC. However, the cross-sectoral activity did not start as expected and the global economic situation affected the resourcing. As a result, the objectives were not entirely met. The evaluation of sectoral research (Finnish Prime Minister's Office 2012) stated: "In the ministries there is not enough CC of the research and they do not have enough external financing" (Science and Technology Policy Council 2010, Finnish Prime Minister's Office 2012). The same evaluation emphasised the objective of evidence-informed policymaking more strongly than before. It said: "Sectoral public research faces challenges in verifying from wide phenomena clear causal relations and solutions to problems expected by decision-makers. The time scales are different as well. In the decision-making, one must concentrate on the short-term problems, whereas many social solutions require long-range development and looking to the future." (Harrinvirta 2010). The Advisory Board was closed down 2011 and a new plan on the overall reform of the research institute system and funding (TULA reform) was launched by the Prime Minister's Office in 2013 (REFORM, see Table 2).

The current model of the Finnish research system puts even more pressure on CC. There are special efforts to improve the use of scientific information on which to base societal reforms and policies. New tools have been generated to ensure the societal relevance of public research. With the reform of Finnish public research and funding, the Strategic Research Council has been introduced as a part of the Academy of Finland to promote strategic research and programmes, and mechanisms for short-term governmentally relevant surveys, assessments and forecasts have been strengthened.

At every stage of the structural development of the Finnish research system, $\mathrm{CC}$ is mentioned as one of the key 
factors in the success of sectoral research in its mission to produce policy-relevant research. Similarly, during the whole period, $\mathrm{CC}$ has been seen as a target for improvement.

The purposes of this empirical study are: 1) to clarify the concept of commissioning competence (CC) and the key factors in building CC and, based on this, 2) to look at how the requirements towards the concept have evolved during the structural development of the public research system, how $\mathrm{CC}$ has been considered in development, and 3 ) to determine what will be required of $\mathrm{CC}$ in the new era of the Finnish public research system.

The starting hypothesis is that it has been difficult to meet interconnected and horizontal research challenges in the structural development of Finnish public research because commissioning competence focus has been too sectoral. The research system level focuses on public sectoral research in Finland, using examples from the environment and natural resources sectors. This study covers the areas of natural resources and environmental policy, as they, together with the social and health sectors, have been under pressure from research policy measures to move towards a more coordinated and horizontal approach.

\section{Materials and Methods}

Qualitative data were generated in semi-structured face-to-face interviews. The informants were 19 experienced high-level research management officials, managers or directors in the public sector. The interview was structured on factors influencing attitudes towards different objectives in different phases of Finnish public research development and measures promoting it like networking, steering and evaluations. The thematic pre-structure of the interview was as follows: Background of the informant, horizontal development of public research, performance control, steering and joint steering, cross-sectoral needs in future, and summary. The overview reports of the national state of Research and Innovation Policy made by the Research and Innovation Council (former Science and Technology Council, published every third year) were used as main background material for the interview form. All informants were currently working, or had formerly worked, in the field of public research management for several years. The choice of experts was based on pre-interviews (at the Research and Innovation Council, the Prime Minister's Office, the Ministry of Agriculture and Forestry and the Ministry of the Environment, one person per institute), which were done beforehand to locate people who have played key roles in structural developing processes of public research in Finland. The method of sampling was a snowball sampling (Parker et al. 2019), with carefully avoiding over-representation of any organisation among informants. The population from which the sample was taken was limited to the workers of three ministries (Ministry of Environment, Ministry of Agriculture and Forestry, and Ministry of Transport and Communications) and two research steering policy agencies (Research and Innovation Council, Prime Minister's Office). The sample was chosen to reflect variation in the role and level of the research system and role in the structural development process. These informants represent two groups in relation to their practical experience of and expertise in the study system: 1) the officials and managers who are involved in a sectoral research steering process at ministerial level, and civil servants in ministries (a total of nine interviewees), 2) the research policy experts or developers of the research system level at the Prime Minister's Office or the Research and Innovation Council (a total of ten interviewees). Most of them (14 persons, 73\%) have worked and experienced the whole period of the structural development of the public research system.

All the participants were informed beforehand of the questions and of the anonymity of the interviews' results. For ethical questions, a member of an ethical committee was consulted. According to the consultation, there was no need to apply for an approval of the ethics committee (Finnish Advisory Board on Research Integrity 2009). Permission to record the interviews was obtained from the participants. The recorded sessions were transcribed, and the data analysed by common thematic analysis (familiarisation-coding-generating themes-reviewing-naming). The interviews were made in Finnish, so no direct quotations are presented in this paper. The interviews were conducted during 2013. The data collection will not extend beyond 2013 for a full-time analysis. In this respect, the information has been supplemented by using the publications of the assessment of the Finnish public research reform as secondary data (Haila et al. 2018). The transcribed material was grouped using Nvivo10 software (Bazeley and Richards, 2000). The core meanings were identified, and thematic expressions given to them. Thematic expressions were aggregated and further combined into the main groups. After the first analyse round of analysis steering as the main theme was changed to the commissioning competence because that has clearly the issue instead of the steering protocol.

The concept of CC was constructed including each of the informants' views to the concept components. First, the pre-structure was formed into three components: relevance-validity-procurement. For distinguishing particularly the nature of sectoral research, the concept's dimensions policy-specific needs, cooperative requirements and science advice were re-formed. The vertical dimension means the knowledge flow from science providers to its 
users in policymaking. Horizontal dimension means cross-sectoral co-operation.

After the evolution of the structural development was drafted based on the Technology and Innovation Council reports (years 1993, 1996, 2000, 2003, 2006, 2008, 2011), the informants' coded views of CC were put to the timeline to establish possible issues and measures of development. Finally, informants' open word comments, which were not linked to development, history or definition of CC were coded and clustered. The main thematic topic which integrates and rises from these views, was an issue about an unclear or constantly changing operating environment of the research management, both inside the research system but also as a pressure coming from outside. The primary interview material covers the development period well until the TULA reform in year 2013 and to analyse the situation after the reform, reports Assessment of research institutes and funding reform (Haila et al. 2018) and KOTUMO Steering group report (Ministry of Education and Culture 2018) were used as supplementary materials.

\section{Results}

\subsection{The Concept of Commissioning Competence}

A total description of the commissioning competence (CC) concept with several components and dimensions was formed by clustering different informants' viewpoints on CC (Table 1).

Informants saw commissioning competence as necessary for organising public research in varied ways, but everyone agreed that it is not a personal ability but should be seen more as a collective competence and organisational performance.

Table 1. The dimensions of commissioning competence (CC) in a context of the management and steering of public sectoral research ( $\mathrm{N}=19$ informants).

\begin{tabular}{|l|l|}
\hline Competence components & Dimension \\
\hline Substance & $\begin{array}{l}\text { Sectoral needs. What research information is needed in one's own } \\
\text { administrative branch? What information and knowledge already exists? } \\
\text { Scientific quality and key actors. }\end{array}$ \\
\hline $\begin{array}{l}\text { Horizontal needs. General understanding of what research information } \\
\text { is needed based on jointly defined needs. Research needs arising from } \\
\text { the implementation of EU and international legislation. }\end{array}$ & $\begin{array}{l}\text { Vertical preconditions. Policy relevance and support for decision- } \\
\text { making. Promotion of interactions between research and policymakers. }\end{array}$ \\
\hline $\begin{array}{l}\text { Foresight and effectiveness. Scientific information that is needed in the } \\
\text { future (foresight). Impacts of previous science. }\end{array}$ \\
\hline Functional & $\begin{array}{l}\text { Methodological limitations. General capability of science to generate } \\
\text { solutions, probability and time scale. Availability of research "markets" } \\
\text { (knowledge of the relevant scientific communities). Research integrity } \\
\text { and ethics. }\end{array}$ \\
\hline $\begin{array}{l}\text { Steering and collaboration. Supervision and control of commissioned } \\
\text { research actions. Co-operation with various commissioners. }\end{array}$ \\
\hline Procurement & Management of the public procurement process. \\
\hline
\end{tabular}

Based on the classifications of the answers, three components of commissioning competence were outlined: content (substance) competence, functional expertise, and procurement competence.

Understanding what kind of research data is needed and how it is obtainable (the need for information and application) is substance competence. It extends to two dimensions: firstly, a single administrative sector and its information needs (sectoral) and, secondly a broader horizontal view of the research needs of each society policy. In addition, vertical expertise is needed in understanding the means and type of information that can be transferred to decision-making. Thus, the commissioner manages the chain from the policy level needs to the research producers. In this context, some informants highlighted evidence-based policy as an example of what the international climate panel IPCC has presented and promoted. According to these informants, social policy will increasingly be based on evidence-informed decision-making, but it requires more effort and promotion of all 
kinds of interactions between the research world and politicians. Familiarity with international knowledge production and know-how was also considered important, because most of the new information for societal needs are produced abroad. This is also linked to anticipating societal needs and research trends, which can be seen also as a dimension of the substance competence.

Functional expertise means that a commissioner understands the nature of the science and its applicability, the validity of the research data that can be used in the decision-making process, and a proper timescale for surveying or reviewing the new data. Normally this is gained by a scientific background of the commissioner. Thus, they know principles of research practices and methods, their possibilities and limitations. Additionally, market management, i.e. knowledge of where the best and most appropriate research know-how in the field lies (knowledge of the research communities), belongs to this component. Another part of functional expertise are research management skills: how to lead, steer, co-ordinate and manage the research process inside the administration.

Procurement process management was seen as a routine, which is mainly taken care of by other staff than research executives. There are still some needs for improvement of competence in procurement and management. For example, in the work of the Sectoral Advisory Board, difficulties were encountered in finding practices for managing the joint funding of ministries. It was also mentioned that the calls for tenders are too often copied from previous rounds, and the call texts should be more explicit so that there is no room for confusion, interpretation or misunderstandings.

\subsection{Time Scale and Development Efforts 1990-2013}

In order to gain an analytical view of the role of $\mathrm{CC}$ in the process, the structural development time of the public research system was divided into three periods according to the main development objectives and mechanisms. The structural development model was either the market model, consortia model or reform model (see Table 2). Using the formulated CC concept as a key, the different stages of the structural development of the sectoral public research system were compared to the components of the CC concept (Table 2.). An issue that arose during interviews was the question of the visible role of $\mathrm{CC}$ in the development periods and why it does not seem to have been solved sufficiently over the years, even though clear improvements have been made like hiring research managers with scientific background to the ministries. 
Table 2. The evolution of role and space of the commissioning competence at different stages of the structural development of sectoral research in public research system Finland

\begin{tabular}{|c|c|c|c|}
\hline & GENERAL 1990-> & BOARD 2003-> & REFORM 2013-> \\
\hline $\begin{array}{l}\text { Main objectives of } \\
\text { the structural } \\
\text { development }\end{array}$ & $\begin{array}{l}\text { Ensuring } \\
\text { competitiveness, } \\
\text { societal relevance and } \\
\text { critical mass of research } \\
\text { institutions. }\end{array}$ & $\begin{array}{l}\text { Ensuring competitiveness, } \\
\text { societal relevance and } \\
\text { critical mass of research } \\
\text { institutions. Development of } \\
\text { horizontal, cooperation to } \\
\text { meet cross-sectoral } \\
\text { challenges. }\end{array}$ & $\begin{array}{l}\text { Ensuring competitiveness, } \\
\text { societal relevance and } \\
\text { critical mass of research } \\
\text { institutions. Greater } \\
\text { prominence for the science } \\
\text { in policy process. }\end{array}$ \\
\hline Mechanisms & $\begin{array}{l}\text { Open network, market } \\
\text { mechanism, self- } \\
\text { organisation inside the } \\
\text { research system. }\end{array}$ & $\begin{array}{l}\text { Purchase-provider model, } \\
\text { cooperation, self- } \\
\text { organisation inside the } \\
\text { research system. }\end{array}$ & $\begin{array}{l}\text { Governmental reform } \\
\text { decisions outside of the } \\
\text { research system. }\end{array}$ \\
\hline $\begin{array}{l}\text { Structure and } \\
\text { commissioning of } \\
\text { sectoral research }\end{array}$ & $\begin{array}{l}\text { Commissioners: } \\
\text { Ministries. Providers: } \\
\text { all relevant research } \\
\text { actors not only from } \\
\text { public research } \\
\text { institutes. }\end{array}$ & $\begin{array}{l}\text { Commissioners: Ministries } \\
\text { and Cross-sectoral funding } \\
\text { consortia (ministries and } \\
\text { research funders) } \\
\text { Providers: cross-sectoral } \\
\text { research consortia } \\
\text { (institutes, universities etc.). }\end{array}$ & $\begin{array}{l}\text { Commissioners: Ministries, } \\
\text { Strategic Research } \\
\text { Council, other } \\
\text { governmental research } \\
\text { programmes. }\end{array}$ \\
\hline $\begin{array}{l}\text { Funding scheme: } \\
\text { Institutional money } \\
\text { vs programme } \\
\text { money }\end{array}$ & $\begin{array}{l}\text { Shift from mainly } \\
\text { institutional money to } \\
\text { more competitive } \\
\text { scheme. }\end{array}$ & $\begin{array}{l}\text { Shift to the joint use of } \\
\text { institutional money - joint } \\
\text { programming. }\end{array}$ & $\begin{array}{l}\text { Less institutional money } \\
\text { but strategic and societally } \\
\text { relevant programmes. }\end{array}$ \\
\hline Challenges & $\begin{array}{l}\text { Funders' commitment } \\
\text { to open contracting. } \\
\text { General performance } \\
\text { management reform in } \\
\text { public admin, which } \\
\text { caused closer steering } \\
\text { of the research institutes } \\
\text { by the Ministries. }\end{array}$ & $\begin{array}{l}\text { Structure and size of the } \\
\text { board (consortia) -> } \\
\text { decision-making issues at } \\
\text { purchaser level. } \\
\text { Lack of power of the } \\
\text { horizontal board compared } \\
\text { to sectoral needs. }\end{array}$ & $\begin{array}{l}\text { Adoption of new } \\
\text { instruments and structures. } \\
\text { Diverse operating field for } \\
\text { commissioners. }\end{array}$ \\
\hline Main $\mathrm{CC}$ dimensions & $\begin{array}{l}\text { Sectoral substance and } \\
\text { quality insurance on } \\
\text { knowledge. }\end{array}$ & $\begin{array}{l}\text { Sectoral substance and } \\
\text { horizontal needs. }\end{array}$ & $\begin{array}{l}\text { Vertical: policy relevance, } \\
\text { strategic view. }\end{array}$ \\
\hline CC- improvement & $\begin{array}{l}\text { Hiring research } \\
\text { managers and } \\
\text { responsible research } \\
\text { officials (executives) to } \\
\text { Ministries. }\end{array}$ & $\begin{array}{l}\text { Joint planning, programming } \\
\text { and co-operative efforts. }\end{array}$ & $\begin{array}{l}\text { Adoption of co-creative } \\
\text { and science-advice } \\
\text { methods, joint } \\
\text { programming. }\end{array}$ \\
\hline
\end{tabular}

Note: GENERAL = general model time 1990->, BOARD = time of sectoral consortia 2003->, REFORM = new model after the reform of research system structure and funding 2013 ->

When looking at the $\mathrm{CC}$ requirements for different models, there is no clear difference between the periods, and it does not seem to offer a clue to the CC issue. However, there are differences at the focus of CC. Based on the background literature (structural development reports, policy decisions), one could say that the purpose of the general model was to focus on the content and science. One of the main objectives was ensuring and developing the scientific quality of the sectoral research. Functional expertise (collaboration and research capability) has been important during each development phase, but during the consortia time, emphasis was placed on horizontal cooperation particularly in terms of cross-sectoral steering capacities. The last period emphasises above all the 
science-advisory process, which means vertical and impact expertise in CC components, as well as increasing policy relevance, which has been a fundamental objective of all public research activities.

In addition, the need to improve $\mathrm{CC}$ was one of the main objectives on the shift from general model to networkbased consortia model. One informant clarifies this in the following way (author's translation): "The fact that the ministries would have actively built that research competence for themselves, a competence that would have made them utilise the resources of these research institutes, was missing. Also missing was the ability to operate in that environment or in the research market so that they would be able to make those orders from the separate sides according to where the best competence was available."

In terms of functional component, there was an unbalance between horizontal research needs and sectoral administration culture. As significant for horizontal coordination is that the requirements for good research cooperation have not been clearly aligned and the requirements have been considered too great for the resources. There are the perceived problems of time scale, as well as incompatibility of the operations, of the objectives, and of the executing organisations. Wider horizontal subjects require long-term studies with resources at their disposal. Another point is that the development of CC did not proceed in the desired way. In addition to being scientifically valid, the commissioned research also needed broader expertise. The requirement for horizontality means, not only multidisciplinary, but also an understanding of the phenomena under investigation from the perspective of several policy sectors. One minor thing is that there have not been clear practices for resource sharing between ministries.

The primary interview material is not sufficient for deeper analysis of the situation after TULA- reform 2013. According to the evaluation of the reform (Haila et al. 2018), new programming instruments, in which policyrelevant research commissioning is based on the co-creative actions of several policy sectors, have been appropriate. However, there was still a need for deeper horizontal cooperation especially between ministries in steering of the research system (Ministry of Education and Culture 2018).

No clear evidence emerged that the success of the structural development phases was dependent on CC. However, one can say that requirements for $\mathrm{CC}$ have evolved during the structural development time (Figure 1.) and that might be one reason why the importance of $\mathrm{CC}$ has been emphasised through the time. Moreover, the informants brought up the subject of an ever-changing operating environment, which constantly challenges commissioning competence.

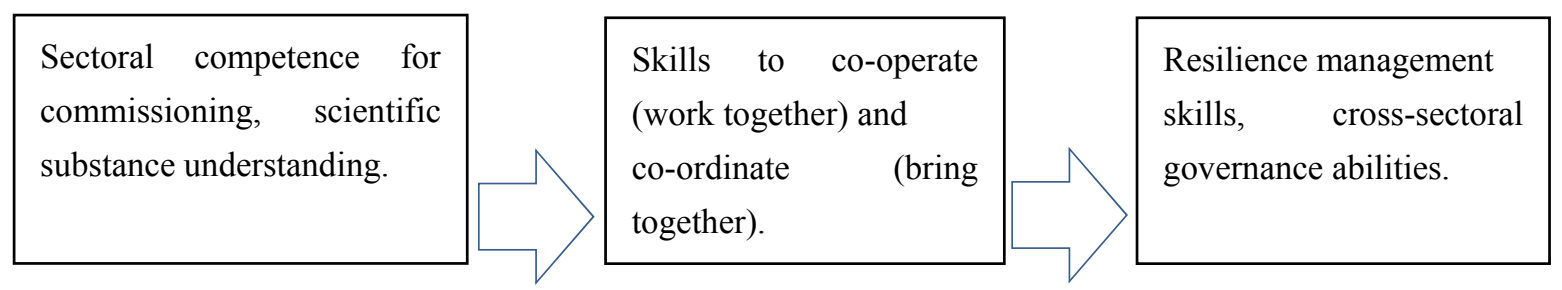

Figure 1. The evolution of requirements for the commissioning competence from the sector-specific to the complexity competence

\subsection{The Challenge of the Changing Operating Environment - towards Complexity Approach}

The steering of research activities in a continuously changing and complex operating environment was seen as especially challenging (at programme level). There are factors and actors that are not controllable. Inside the policy sector the challenge lies particularly in the emergent unexpected research needs. One has to try to keep the balance between research and monitoring inside the sector and balance between them with external needs coming from other policy sectors. In addition, there are needs for research and cooperative actions coming from the international policies like the European Union, and from the governmental policy outlines like new governmental level programmes and cooperative measures.

Figure 2 shows the management or operating environment with affecting policies pictured according to the informants' descriptions. The figure shows as an example the scope of a manager responsible for the environmental sector. 


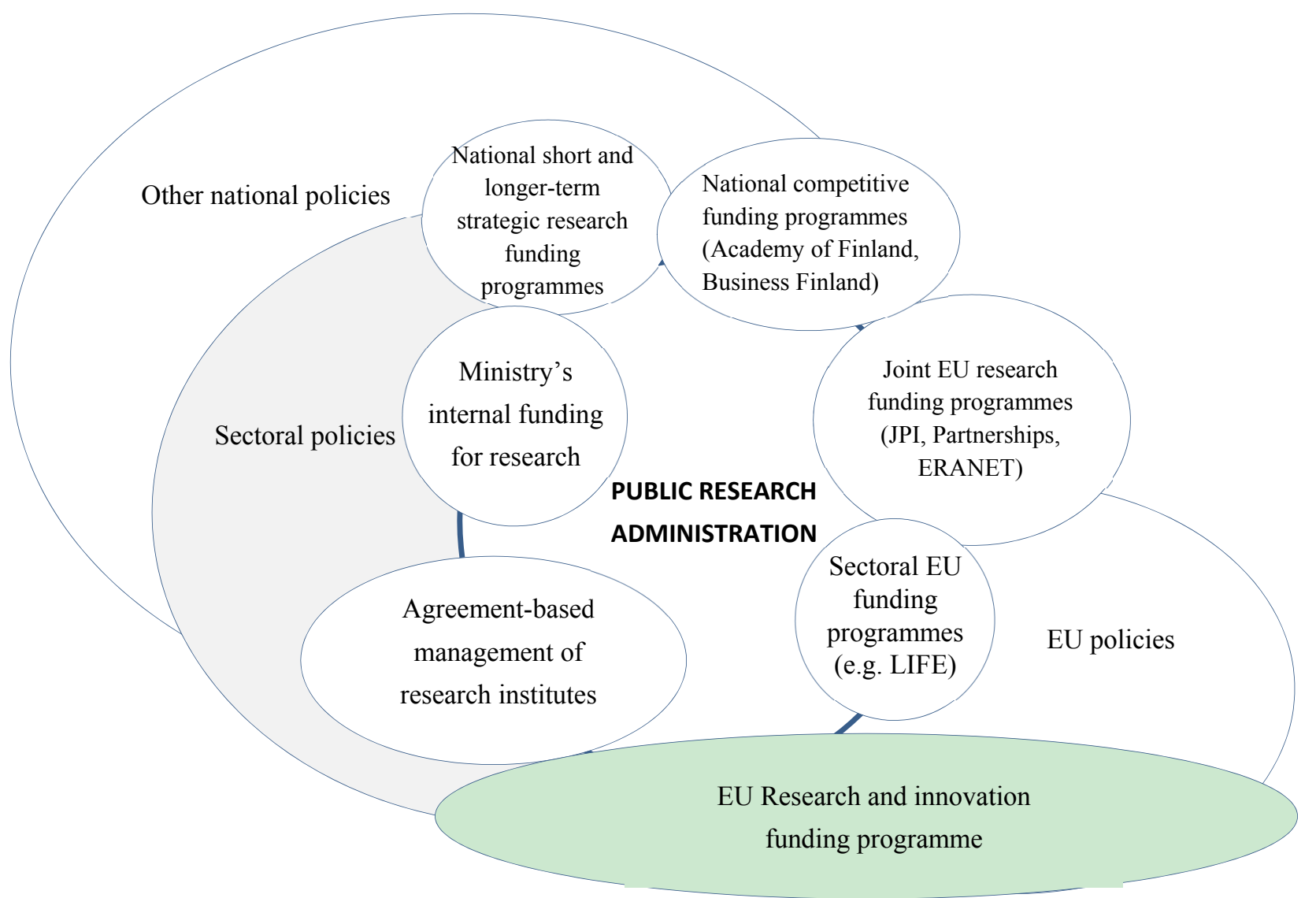

Figure 2. The complex operating environment of public research administration in the field of environmental and nature resources policy. There are various policy needs and programmes to be considered in management, cooperation, and planning of policy-relevant knowledge commissioning both within and outside of the policy sector

The operating environment of managers is a jungle of programmes and policies. Managers must deal with their own sector programme management, but the further a certain programme goes from the sector, the more uncertain the operations are. Managers were aware of the problems of cooperation and networking. Research managers deal with networks all the time. Concerning the control of networks, the answers varied even between the main groups. Usually they considered the networks as a solution when the matter did not belong to their own sector of administration or, more naturally, when it required international cooperation. On the other hand, almost all the managers saw their work as network or co-operation management. This is closely connected to effectiveness; how can the research be commissioned so that its results can be put into practice and form the basis of decision-making as easily as possible. Since the interviews, this matter has been the subject of heated debate in Finland and in the EU, and several things have been suggested to improve science-advising processes (Topp et al. 2018). Research institutes have strongly argued that the sector-specific research they carry out is, in principle, applied research, and research institutes have traditionally played a role in interpreting scientific knowledge for decision-making.

\section{Discussion}

Although the issue has been visible for thirty years, this is the first study on the commissioning competence needed to steer public research in Finland. CC has been examined in other contexts and other public services, mainly in the field of health care (McCafferty et al 2012), but the studies and the literature on commissioning the research services are rare and the commissioning guidelines have been made for the quality assurance of the process. The purpose of this study was to examine the role of the $\mathrm{CC}$ in the reform of the public research system. The result of the analysis does not fully support the research hypothesis as the development of $\mathrm{CC}$ has not been one of the main drivers, but rather the need for $\mathrm{CC}$ has co-evolved along the way with the significance of the research information within each public sector.

The research managers and research executives in public research are the key actors in the research commissioning 
process, and their ability to operate on multiple levels and dimensions in a constantly changing environment is crucial for the functionality of the interaction between scientists and decision-makers. This study shows that the question of $\mathrm{CC}$ is significantly broader than knowing the content and managing the procurement process. The concept of CC has been introduced in this article. In summary, CC plays a role in the process in which scientific knowledge is acquired and turned into policy measures. It considers several dimensions: research itself, related international and national background policies, future needs, time scale - altogether a very challenging combination to manage. $\mathrm{CC}$ can be understood comprehensively as a personal or organisational combination of knowledge acquisition skills, strategic planning, policy-setting and cooperation. This means capability to accomplish the challenging task of managing collaboration and producing usable research-based knowledge for current situations in a changing operating environment. In addition, when major parts of major societal challenges are horizontal and effectiveness of science-advice processes are unclear, this will create an even more challenging and complex operating environment for CC. In the evidence-informed or science-informed policy context, findings of this study support the criticism of an excessively linear approach to evidence-based policy (Cairney, 2016).

\subsection{How to Cope with a Changing Environment - Resilience Management}

In a small, open economy, future needs are related to focusing on national critical masses, the most promising and qualified niche areas, and the benefit of international research collaboration. Finland being a member state of the European Union, an additional challenge arises from the successful integration, reconciliation and balancing of innovation policies and related resources between national and EU activities. As described in previous chapters, $\mathrm{CC}$ is a combination of research competence and network management in an emerging and changing operating environment.

Previous literature shows that the research and innovation system has characteristics of a complex adaptive system. A complex system dynamically evolves in non-linear ways, giving it unique properties that distinguish it from other systems (Katz 2016). Scale-invariant emergent properties are a common feature of complex systems (Katz 2016). In fields like the environment and natural resources, there are always emergent phenomena, which are born or created invisibly and appear unexpectedly. The research and the decision-making systems must be adaptive to different situations. What factors encourage these properties of the study system to appear and emerge, if necessary? It is not a new thing to define a public administration system as complex (Eppel 2017, Klijn 2008, Morçöl 2005), but the key question is how to manage key factors of the system to maintain its functionality. There should be a capacity to react to these effects - to formulate actions for the better complex problem- management skills.

The concept of resilience has been introduced in several disciplines to define this capability. Its origin is in biology, but it is known both in social and natural sciences as well as in technology and engineering. Resilience is defined as an ability of a system to withstand changes in its environment and still function (Biggs et al. 2012). Typically, resilience has been divided three concepts: engineering resilience (Pimm 1984), ecological resilience (Holling 1973) and social-ecological resilience (Folke et al. 2002). Resilience approach is a common concept in change management in land-use planning. This study approaches the matter from the research managerial point of view when implementing science-informed policy. Although care must be taken in comparing social-ecological systems with the system of governance (especially deterministic assumptions, see Duilt 2016), the management of public research and land-use planning could be considered as very similar processes. In land-use planning, resilience maintenance has been found to be a major factor in maintaining the functionality of the site under different pressures (Biggs et al. 2012). The situation is very similar when one thinks about what is needed from research management to favour resilience, to make the system adaptive but, at the same time, maintain essential research services in a continuously changing operating environment? This approach is close to the social-ecological concept in which resilience is a concept of adaptability, the capacity to cope with the unexpected in such a way that core values are preserved (Van Gunsteren 2006. See also Fisher 2015.). The use of the term 'governance' helps to capture these aspects where a multitude of actors interact in both formal and informal ways. The concept of governance is used not only to describe informal types of cooperation or state policy implementation but also regulation of social behaviour through networks and other non-hierarchical mechanisms (Fukuyama 2016). In the research world, "research governance", i.e., considering the resilient characteristics of management actions, bridges the gap between a complex system, unexpected environment, and productive research management. The tools of governance enable the maintenance of adaptability and the resilience of a system where cooperative elements play essential roles. The managers are those in key positions in the management of research policy, both on a steering level and within their policy sectors. 
Table 3. How to beat the complexity? A general model of the demands on a research manager based on the resilience management in a social-ecological system

\begin{tabular}{|c|c|c|}
\hline Measure & In research management context & In planning and decision-making \\
\hline $\begin{array}{l}\text { Maintain diversity } \\
\text { and redundancy }\end{array}$ & Multidisciplinary & Diversity in research capacities \\
\hline Manage connectivity & Cooperation and social networks & $\begin{array}{l}\text { Support interactions and horizontal } \\
\text { activities, networks, interorganisational } \\
\text { collaboration }\end{array}$ \\
\hline $\begin{array}{l}\text { Manage slow } \\
\text { variables and } \\
\text { feedbacks }\end{array}$ & $\begin{array}{l}\text { Research education and capacity } \\
\text { building }\end{array}$ & $\begin{array}{l}\text { Consider time scale - forecast and } \\
\text { evaluate, be aware of science and } \\
\text { technology studies }\end{array}$ \\
\hline $\begin{array}{l}\text { Foster complex } \\
\text { adaptive systems } \\
\text { thinking }\end{array}$ & $\begin{array}{l}\text { Accept uncertainty, open-endings, and } \\
\text { non-logical processes }\end{array}$ & $\begin{array}{l}\text { Understand and highlight } \\
\text { unpredictability, uncertainty, and } \\
\text { interdependence }\end{array}$ \\
\hline Encourage learning & $\begin{array}{l}\text { Support researchers' education, } \\
\text { multidisciplinary, peer-support and } \\
\text { feedback systems }\end{array}$ & Evaluate, try, follow/monitor \\
\hline Broaden participation & $\begin{array}{l}\text { Promote co-creation and participatory } \\
\text { methods }\end{array}$ & $\begin{array}{l}\text { Novel methods in research programme } \\
\text { planning }\end{array}$ \\
\hline $\begin{array}{l}\text { Promote polycentric } \\
\text { governance systems }\end{array}$ & Multi-level governance structures & Network management \\
\hline
\end{tabular}

NOTE! Measures are modifications based on Biggs et al. 2012 and Seven principles for building resilience in social-ecological systems: https://applyingresilience.org/en/start-en/.

Based on a multidimensional view of commissioning competence, a complex research environment can be managed in accordance with a framework built to manage a complex adaptive system in land-use scenarios (Table 3). Transferring the governance-by-resilience approach from the land-use planning context to the research management context seems usable. Maintaining and managing diversity, connectivity, feedback and governance are key words, as are decentralisation and collaboration.

As shown by the comparison in Table 3, in terms of research, diversity and the management of uncertainty through collaboration operate in the same way. It seems that, instead of direct tools, methods of governance are needed. Already the character of complexity means that simple or all-embracing guidelines cannot be given, except on a general level (Teisman 2008, Teisman and Klijn 2008). The problems are wicked and rarely completely solved (Daviter 2017). The command and control of the management arrangement do not operate, the environment changes all the time, and adaptive measures and methods are needed. In public administration, it has been shown that network management or governance form part of the complexity management (Sørensen and Torfing 2007a, 2007b, Daviter 2017).

It looks that the social-ecological resilience concept and resilience maintenance by governance are useful analogies when filling the gap between research management and its complex environment. Governance requires collaboration, but studies have shown that various types of stakeholders are not necessarily willing to deliberate and contribute to jointly negotiated solutions (Bodin 2017). The concept of the collaborative public manager introduced in the planning context in recent years (Bodin 2017, O’Leary \& Vij 2012) is also suitable for the research management. The field at the interface of research management and sector administration is wide and the demands for knowledge challenging. The knowledge of the substance itself is only half of the picture; another side is cooperation capability (achieving operative cooperation, linking multidimensional policy and research objectives, bringing together multilevel actors, communication) (Figure 2) and coordination (Vermeiren 2021). Sectoral skills are still key competencies of the administration, but coordination and uncertainty management are also essential, as well as, on a wider scale, understanding the decision-making process and the principles of 
networking. What are they and what is required from the coordination and steering of cooperation, i.e., the governance of national and international networks (see also Hansen and Villadsen 2017) and from the role of scientific information (Newman \& Head 2017) in evidence-informed policy making (Ansell \& Geyer 2017)? How can the actors be bound together, affect operations and commitment, and how are the national and international operations connected?

\section{Conclusion}

Based on the analysis of this study, we can follow the development of the term commissioning competence and of its needs at different stages of the structural development in the Finnish public research system. The content of commissioning competence has evolved with the structural development of the public research system from silos to a horizontal view and with the need to research information in public policy processes. The meaning of commissioning competence has evolved from research and scientific expertise itself to the management of the entire process and data usability in the policy advice process. Since the last structural reform in 2013, the public research action's emphasis has been more on managing the operating environment and policy-advice structures (Haila et al. 2018). We are seeing that complexity thinking with a pragmatic management twist is gaining ground in public administration (e.g. Raisio \& Lundström 2015), as are the phenomenon-based politics (Kotiranta 2019) as well. The boundaries between the academic commissioner and the sectoral policy commissioner as well as between their operational environments is blurring. The tool is to focus on shared programmes prepared by cocreation methods and for ministries to act as policy experts in these research or innovation programmes. This means a constantly increasing demand for competence to complexity thinking and resilience management both in personal and at organisational level.

\section{Acknowledgements}

The author thanks Professor Erkki Alasaarela (University of Oulu) and the editorial board and anonymous referee for their valuable comments to the manuscript. The interviews were funded by the VERKA ESF project (S11458).

\section{References}

Academy of Finland. (2009). The State and quality of scientific Research in Finland 2009. Publications of the Academy of $\quad$ Finland, $10 / 09 . \quad$ Retrieved from https://www.aka.fi/globalassets/awanhat/documents/tiedostot/julkaisut/sight_2009_english_ebook.pdf

Ansell, C., \& Geyer, R. (2017). Pragmatic complexity' a new foundation for moving beyond 'evidence-based policy making'? Policy Studies, 38(2), 149-167. https://doi.org/10.1080/01442872.2016.1219033

Banks, G. (2009). Evidence-Based Policy Making: What is It? How Do We Get It? ANU Public Lecture Series, Productivity Commission Canberra, February 2009. Retrieved from https://ssrn.com/abstract=1616460

Bazeley, P., \& Richards, L. (2000). The NVivo qualitative project book. London: SAGE Publications.

Biggs, R., Schlüter, M., Biggs, D., Bohensky. E. L., Shauna, B. S., Cundill, G., Dakos, V., Daw, T. M., Evans, L. S., Kotschy, K., Leitch, A. M., Meek, C., Quinlan, A., Raudsepp-Hearne, C., Robards, M. D., Schoon, M. L., Schultz, L., \& West, P. C. (2012). Towards principles for enhancing the resilience of ecosystems services. Annual Review of Environment and Resources, 37, 421-448.

Bodin, Ö. (2017). Collaborative environmental governance: Achieving collective action in social-ecological systems. Science, 357(6352). https://doi.org/10.1126/science.aan1114

Brownson, R. C., \& Jones, E. (2009). Bridging the gap: Translating research into policy and practice. Preventive Medicine, 49, 313-315. https://doi.org/10.1016/j.ypmed.2009.06.008

Brownson, R. C., Chriqui, J. F., \& Stamatakis, K. A. (2009). Understanding Evidence-Based Public Health Policy. American Journal of Public Health, 99, 1576-1583. https://doi.org/10.2105/AJPH.2008.156224

Cairney, P. (2016). The politics of evidence-based policy making. Introductory chapter. Book. Springer https://doiorg/ 10.1093/acrefore/9780190228637.013.268

Daviter, F. (2017). Coping, taming or solving: alternative approaches to the governance of wicked problems. Policy Studies, 38(6), 571-588. https://doi.org/10.1080/01442872.2017.1384543

Duilt, A. (2016). Resilience Thinking: Lessons for Public Administration Public Administration, 94(2), 364-3801. https://doi.org/10.1111/padm.12182

Eppel, E. (2017). Complexity thinking in public administration's theories- in-use. Public Management Review, 19(6), 845-861. https://doi.org/ 10.1080/14719037.2016.1235721 
Finnish Advisory Board on Research Integrity. (2009). Ethical principles of research in the humanities and social and behavioural sciences and proposals for ethical review. Retrieved from https://www.tenk.fi/en/tenkguidelines

Finnish Prime Minister's Office. (2012). State research institutes and research funding: proposal on a comprehensive reform. Prime Minister's Office Publications 3/2012. Edita Prima, Helsinki. In Finnish with English Summary.

Fisher, L. (2015). More than 70 ways to show resilience. Nature 518, 35. https://doi.org/10.1038/518035a

Folke, C., Carpenter, S., Elmqvist, T., Gunderson, L., Holling, C. S., \& Walker, B. (2002). Resilience and sustainable development: building adaptive capacity in a world of transformations. Ambio, 31(5), 437-440.

Fukuyama, F. (2016). Governance: What Do We Know, and How Do We Know It? Annual Review of Political Science, 19, 89-105. https://doi.org/10.1146/annurev-polisci-042214-044240

Haila, K., Aarrevaara, T., Hjelt, M., Paavola, H., Palomäki, S., Pulkkinen, K., Raivio, T., Rannikko, H., Sepponen, S., \& Valtakari, M. (2018). Assessment of the research institutes and funding reform. Publications of the Government's analysis, assessment and research activities 74/2018 (In Finnish with English abstract).

Hansen, M. B., \&Villadsen, A. R. (2017). The external networking behaviour of public managers - the missing link of weak ties. Public Management Review, 19(10), 1556-1576. https://doi.org/10.1080/14719037.2017.1299200

Harrinvirta, M. (2010). Evaluation of the Advisory Board for Sectoral Research. Advisory Board for Sectoral Research 7/2010. In Finnish with English Summary.

Head, B. W. (2010). Reconsidering evidence-based policy: Key issues and challenges. Policy and Society, 29, 7794. https://doi.org/10.1016/j.polsoc.2010.03.001

Holling, C. S. (1973). Resilience and stability of ecological systems. Annual Review of Ecology and Systematics, $4,1-23$.

Hyytinen, K., Loikkanen, T., Konttinen, J., \& Nieminen, M. (2009). The role of public research organizations in the change of the national innovation system in Finland. The Advisory Board for Sectoral Research.

Katz, J. S. (2016). What is a Complex Innovation System? PLoS ONE, 11(6), e0156150 https://doi.org/10.1371/journal.pone.0156150

Klijn, E.-H. (2008). Complexity theory and public administration: What's New? Public Management Review, 10(3), 299-317. https://doi.org/10.1080/14719030802002675

Kotiranta, A., Kronqvist, J., Lerkkanen, L., Pulkkinen, K., Roschier, S., Sepponen, S., Tahvanainen, A. J., \& Valkola, A. (2019). A Phenomenon-Driven Process for Determining National RDI Focus Areas. Publications of the Government's analysis, assessment and research activities 9/2019. 89 p. In Finnish with English summary. Retrieved from http://julkaisut.valtioneuvosto.fi/bitstream/handle/10024/161337/9-2019Ilmiolahtoinen\%20prosessi_TKI.pdf

Lemola, T. (2002). Convergence of national science and technology policies: the case of Finland. Research Policy, $31,1481-1490$.

Loikkanen, T., Hyytinen, K., Konttinen, J., \& Pelkonen, A. (2010). Internationalization of Finnish Public Research Organisations - Current state and future perspectives. The Advisory Board for Sectoral Research 3-2010. Retrieved https://www.researchgate.net/publication/242545885_Internationalisation_of_Finnish_Public_Research_Or ganisations

McCafferty, S., Williams, I., Hunter, D., Robinson, S., Donaldson, C., \& Bate, A. (2012). Implementing world class commissioning competencies. Journal of Health Services Research and Policy, 17(Suppl 1), 40-8. https://doi.org/10.1258/jhsrp.2011.011104.

Ministry of Education and Culture. (2018). KOTUMO, a multi-annual process for deepening cooperation between higher education institutions and research institutes 2014-2017. Publications of the Ministry of Education and Culture, Finland 2018:7. In Finnish with English summary. Retrieved from http:/urn.fi/URN:ISBN:978952-263-549-5

Morçöl, G. (2005). A new systems thinking: Implications of the sciences of complexity for public policy and administration. Public Administration Quarterly, 29(3), 297-320. 
Newman, J., \& Head, BW. (2017). Wicked tendencies in policy problems. rethinking the distinction between social and technical problems. Policy and Society, 36(3), 414-429. https://doi.org/10.1080/14494035.2017.1361635

O'Leary, R., \& Vij, N. (2012). Collaborative Public Management: Where Have We Been and Where Are We Going? The American Review of Public Administration, 42(5), 507-522. https://doi.org/:10.1177/0275074012445780

OECD. (2017). OECD Reviews of Innovation Policy: Finland 2017. OECD Publishing, Paris. https://doi.org/10.1787/9789264276369-en

Official Statistics of Finland. (2020). Government R\&D funding in the state budget [e-publication]. ISSN=24893250. 2019, Government R\&D funding on the increase. Helsinki: Statistics Finland. Retrieved from http://www.stat.fi/til/tkker/2019/tkker_2019_2019-02-21_kat_001_en.html

Parker, C., Scott, S., \& Geddes, A. (2019). Snowball Sampling. SAGE Research Methods Foundations. Online Publication. https://doi.org/10.4135/9781526421036831710

Pimm, S. L. (1984). The complexity and stability of ecosystems. Nature, 307, 321-326.

Raisio, H., \& Lundström, N. (2015). Real leaders embracing the paradigm of complexity. Emergence: Complexity and Organization, 17(3), 1-5. Retrieved from https://www.researchgate.net/publication/286843521_Real_leaders_embracing_the_paradigm_of_complexi ty

Rantanen, J. (2008). Sektoritutkimuksen selvitysraportti. Sektoritutkimuksen neuvottelukunta 1/2008. In Finnish with English summary.

Reale, E. (2017). Analysis of National Public Research Funding - PREF. Final Report. https://doi.org/10.2760/19140

Sørensen, E., \& Torfing, J. (2007a). Introduction Governance Network Research: Towards a Second Generation. In Sørensen, \& Torfing (Eds.), Theories of Democratic Network Governance (pp. 1-21). Springer. https://doi.org/10.1057/9780230625006

Sørensen, E., \& Torfing, J. (2007b). Theoretical Approaches to Metagovernance. In Sørensen, \& Torfing (Eds.), Theories of Democratic Network Governance (pp. 169-182). Springer. https://doi.org/10.1057/9780230625006

Teisman, G. R. (2008). Complexity and Management of Improvement Programmes. Public Management Review, 10(3), 341-359. https://doi.org/10.1080/14719030802002584

Teisman, G., \& Klijn, E. H. (2008). Complexity theory and public management. Public Management Review, 10(3), 287-297. https://doi.org/10.1080/14719030802002451

Topp, L., Mair, D., Smillie, L., \& Cairney, P. (2018). Knowledge management for policy impact: the case of the European Commission's Joint Research Centre. Palgrave Communications, 4, 87. https://doi.org/10.1057/s41599-018-0143-3

Van Gunsteren, H. (2006). Resilience through Governance with Democracy. In Benz A., \& Papadopoulos (Eds.), Governance and Democracy: Comparing National, European and International Experiences (pp. 81-95). London \& New York: Routledge.

Vermeiren, C., Raeymaeckers, P., \& Beagles, J. (2021). In search for inclusiveness: vertical complexity in public - nonprofit networks. Public Management Review, 23(2). https://doi.org/10.1080/14719037.2019.1668471

Virtanen, T. (2016). Finland, active reformer looking for more centralisation and horizontal coordination. In Hammerschmid, G., Andrews, R., Bezes, P., \& Van de Walle, S. (Eds.), Public Administration Reforms in Europe: The View from the Top (pp. 129-139). Edward Elgar Publishing. Cheltenham, UK.

Von Winterfeldt, D. (2013). Bridging the gap between science and decision-making. PNAS August, 20, 110(Supplement 3), 14055-14061. https://doi.org/10.1073/pnas.1213532110

\section{Copyrights}

Copyright for this article is retained by the author(s), with first publication rights granted to the journal.

This is an open-access article distributed under the terms and conditions of the Creative Commons Attribution license (http://creativecommons.org/licenses/by/4.0/). 